\title{
Conceptual Manipulation and Semantic Distinctions in Mandarin Verb Complements: The Contrast between shàng and dào
}

\author{
HUI-CHEN SABRINA HSIAO \\ University at Buffalo, The State University of New York
}

\section{Introduction}

This study investigates the lexicalization of spatial and aspectual components incorporated in Mandarin verb complements (VCs hereafter) shàng 'up' and dào 'arrive'. The verb complement in Mandarin is well-known as the second verbal element in VV construction. Traditionally, V-shàng and V-dào are categorized as 'directional complements' and 'phase complements' respectively (Chao 1968; Li and Thompson 1981). Both VCs shàng and dào, originally functioning as a main verb (Gao 1995), are similar to the counterpart 'up/on/above/over' and 'arrive/ reach' in English; they have various usages, such as in verb phrases, and prepositional phrases, for example. Although there is no doubt that shàng and dào are poly-functional, it seems that there is no agreement on to what extent particular uses are related to one another. Most of the previous studies focus on the spatial meanings lexicalized in noun phrases and postpositions; they provide explanations based on a metaphorical approach or cultural values. However, such accounts cannot entirely explain the main function of the post-verbal complements shàng and dào in VV construction.

In this paper, I explore the subtle distinctions between the satellites shàng and dào, and provide an explanatory account for their seemingly diverse functions from a cognitive approach. Moreover, this paper aims to offer another perspective on the conceptual properties of spatial and aspectual notions embodied in these two verb complements, and verify evidence that Mandarin treats five framing events as a single conceptual entity.

The organization of this paper is as follows. A brief literature review and the theoretical framework are presented in section 1 . In section 2 , the data involved the verb complements shàng and dào are introduced. In section 3, based on Talmy's (2000) framework and framing event types, I discuss several examples

\footnotetext{
* I would like to thank Leonard Talmy for valuable discussions of this material. I also thank Jean-Pierre Koenig for comments and suggestions. And thanks as well go to Liancheng Chief for helpful discussions. All errors remain my own responsibility.
} 
and account for how aspectual and spatial concepts are explicitly expressed in shàng and dào regarding different framing event types. Section 4 shows a summary of findings and conclusion.

\section{Previous Studies}

The VCs shàng and dào function both as verbs or post-verbal complements; they are two of the most common VCs based on a corpus ${ }^{1}$ search. In previous studies, a set of lexical rules are postulated by Thompson (1973) to explain the VV derivation in Mandarin. However, lexical rules have too many limitations, and they fail to capture subtle distinctions. Teng (1977) generalizes the functions of several verb complements by claiming that shàng and dào both have the semantic property of "contact," but differ in which of the 'movement' feature of the verb $[+/$-movement $]$ is involved. However, this account does not explain the possibility that the same verb occurs with different verb complements. It also fails to explain the aspectual functions among verb complements. In addition, Poteet (1987) does not attempt to account for the phenomena discussed above and only focuses on the characterization of dào. Most studies (cf. Smith 1990; Yong 1997; Kang 2001) agree that Mandarin verb complements denote a new state resulting from the action $\left(\mathrm{V}_{1}\right)$. Other approaches, such as collocation patterns of the two elements (McDonald 1994) or a metaphorical approach (Xing 2000), do not exemplify how the intertwined ranges of functions are conceptually incorporated in verb complements.

Therefore, a detailed semantic analysis of shàng and dào is proposed in section 3. Different from the previous analysis, I adopt Talmy's (2000) cognitive approach (lexicalization patterns) and discuss the semantic components embodied in each verb complement in this paper. Based on Talmy's (2000) claim, languages seem to divide into a two-category typology on the basis of the characteristic pattern where the conceptual structure of the macro-event is mapped onto the syntactic structure. Typology is composed of whether the core schema ${ }^{2}$ is expressed by the main verb or by the satellite. ${ }^{3}$ In general, Mandarin is an example of a satellite-framed language (Talmy 2000), while Spanish is a verb-framed language. Therefore, if this assumption that the concepts are "encapsulated" into the satellite $\mathrm{V}_{2}$ is valid, the next question is what are the essentially underlying conceptual manipulations incorporated in shàng and dào, since there are numerous VCs in Mandarin.

\section{The Data}

In Mandarin, a simple verb is often used with a perfective marker le or a verb

\footnotetext{
1 Sinica Corpus 3.0 http://www.sinica.edu.tw/ftms-bin/kiwi.sh

2 The core schema of the framing event is composed of either the association function alone or the association together with the ground entity (Talmy 2000).

3 The term 'satellite' refers to a surface element in which a connected set of semantic categories that appear lexicalized in a closed-class type (Talmy 2000).
} 
complement in a sentence. The following examples (1-6) are the primary focus of the present paper.

\begin{tabular}{lllll}
\multicolumn{3}{c}{ Simple V } & \multicolumn{1}{c}{ V-shàng 'up' } & \multicolumn{1}{c}{ V-dào 'arrive' } \\
(1) a. piāo & 'float' & b. piāo-shàng & c. piāo-dào \\
$(2)$ & a. zhūi & 'chase' & b. zhuī shàng & c. zhuī dào \\
$(3)$ & a. zhuàng 'bump' & b. zhuàng-shàng & c. zhuàng-dào \\
(4) & a. huā & 'spend' & b. huā-shàng & c. * huā-dào \\
$(5)$ & a. măi 'buy' & b. * măi-shàng & c. măi-dào \\
$(6)$ & a. péi & 'compensate' & b. péi-shàng & c. * péi-dào
\end{tabular}

A closer examination of the data indicates that the semantics and functions of the VCs, shàng and dào, cannot be illuminated by simply combining the two components $\left(\mathrm{V}_{1}-\mathrm{V}_{2}\right)$ together. Scrutinizing the data above, we found that shàng and dào do not all behave the same way with respect to functioning as a post-verbal complement. Several remarkable similarities and dissimilarities are observed. First, both VCs shàng and dào can occur in the same environments, as shown in (1-3). Second, it seems that they are in complementary distribution with each other, as illustrated in (4) and (5). Third, previous accounts cannot explain their non-spatial (aspectual) uses, shown in (4) and (6). One question remaining to be addressed is how to predict their diverse occurrences. In particular, what are the overlapping functions they both have, and what are the distinctive functions and conceptual representations exhibited by each?

\section{A Finer Look: Contrast between V-shàng and V-dào Constructions}

The goal of this section is to capture the subtle distinctions between shàng and dào by means of concrete comparison. In the view of this paper, my discussion is primarily focused on V-shàng and V-dào constructions so that a fine-grained elaboration would clarify these two VCs.

My preliminary proposal is as follows: a) shàng and dào can occur in the same contexts if the spatial notion, such as path or spatial relation between the Figure and the Ground, ${ }^{4}$ is more saliently construed by the speaker than the aspectual notion; b) the crucial distinction between shàng and dào is aspectual, that is, shàng encodes a telic notion and the inchoative/inception of the resultant state, whereas dào merely signals telicity; c) in realization framing events, ${ }^{5}$ dào functions as a fulfillment satellite, whereas shàng is a confirmation satellite as well as a fulfillment satellite, depending on the first verb. These arguments will be elaborated in the following section.

\footnotetext{
${ }^{4}$ The Figure is the salient moving or stationary object in a Motion event whose path or site is the relevant issue. The Ground is the reference object with respect to which the Figure's path/site is characterized.

${ }^{5}$ An event of realization is an encompassive category for a pair of related types, fulfillment and confirmation.
} 


\subsection{Contexts Where Both shàng and dào Can Occur}

Example (7) illustrates a situation where both satellites shàng and dào behave alike in a Motion event. The Motion event consists of a transition by the Figure with reference to the Ground. Basically, the Motion event involves the Figure object changing its position in space in relation to the Ground; the spatial relation between the Figure and Ground is also specified. What these two examples, (7a) and (7b), have in common is that they both express the end (telic) point of an event.
a. Qiqiu
piao-shàng
waitaikong
(qu) le
balloon
float-up
outer space
(go) ASP
'The balloon floated/is floating up to outer space.'
b. Qiqiu
piao-dào
waitaikong
balloon
float-arrive
outer space
(qu) le
(go) ASP

'The balloon floated/has floated up to outer space.'

The Figure in (7) refers to qiqiu 'balloon', whereas the primary reference object (i.e. the Ground) is unspecified. Nevertheless, we can locate the movement of the Figure on the basis of the earth-based reference. The support relation of the co-event is particularized as Manner to the framing event, ${ }^{6}$ and the core schema is WITH-THE-MANNER-OF. As shown in (7a), the aspectual (telic) information as well as the path notion (i.e. the movement of the Figure) is implicated by the use of shàng. That is, the notion of the path is more saliently expressed than the aspectual component in such a motion event with the use of the satellite shàng. By contrast, if the $\mathrm{VC}$ dào is used in (7b), the path notion is not as saliently conveyed as the aspectual notion (telic). The other way to explicate the subtlety is that the employment of dào draws one's attention not only to the ending (telic) of the floating, but also to the final site where the Figure qiqiu 'balloon' is finally located.

However, it is worthwhile to remark that the function of shàng is not limited to specifying the notion of the path only. The satellite shàng also specifies the spatial relation between the Figure and Ground in addition to the path notion. Another framing event, an event of coactivity, is given in (8).
a. Xiaohua
zhui
gongche
Xiaohua
chase
bus
'Xiaohua tries to chase after the bus.'
b. Xiaohua
zhui-le
Xiaohua chase-PERF
gongche
'Xiaohua chased after the bus.'

\footnotetext{
${ }^{6}$ The framing event serves to schematize a conceptual domain, and it is composed of four components: a Figure, and an activating process, an association function, and a Ground.
} 
$\begin{array}{lllll}\text { c. Xiaohua } & \text { zhui-shàng } & \text { (le) } & \text { gongche } & \text { le } \\ \text { Xiaohua } & \text { chase-up } & \text { PERF } & \text { bus } & \text { ASP }\end{array}$

'Xiaohua caught up with/was running over to the bus.'

$\begin{array}{lllll}\text { d. Xiaohua } & \text { zhui-dào } & \text { (le) } & \text { gongche } & \text { le } \\ \text { Xiaohua } & \text { chase-arrive } & \text { PERF } & \text { bus } & \text { ASP }\end{array}$

'Xiaohua caught up with the bus.'

The use of the satellite shàng denotes the spatial relation between the Figure and Ground, and such an event is interpreted as being in a coactivity relation rather than the notion of path. Coactivity is also known as Activity Correlating. It means the first subject performing an activity is associated with the second subject whose activity is correlated with the first. Examples of this can be seen in (8). In example (8), chasing bus, the Figure is Xiaohua and the Ground is gongche 'bus'. The meaning of the simple verb zhui 'chase' in (8a) does not convey the realization of the action of chasing. Moreover, the addition of the perfective marker le leads to a perfective or past tense reading. Besides using le, Mandarin native speakers often use a variety of VCs such as shàng and dào, as exemplified in (8c) and (8d). Both shàng and dào denote the notion of telicity in (8c) and (8d), but only shàng signifies the temporal concept of instantaneous change (i.e. the inception of another change of state resulting from the $\mathrm{V}_{1}$ ).

More importantly, in addition to denoting the telicity, shàng in (8c) also specifies the spatial configuration between the Figure and the Ground (i.e. Xiaohua and the moving bus - a reference object). Two possible conceptions are often associated with the use of the satellite shàng. First, it can be the case that the event of the Figure and the Ground has an inchoative aspectual reading - a correlative view is emphasized. Second, it is also possible to construe a situation where the agent Xiaohua (the Figure) is jumping onto the bus (the Ground) if the satellite shàng is used. For the VC dào, only the aspectual (telic) notion is incorporated; there is no spatial concept associated with dào.

The last example of the spatial use of VCs in a motion event involves the semantic notion of contact (cf. Teng 1977).
a. Zhangsan
zhuang
le
Zhangsan
bump
PERF
anquandao
'Zhangsan bumped into the median.'
b. Zhangsan
zhuang-shàng
le
PERF
anquandao
Zhangsan
bump-up
'Zhangsan drove over/bumped into the median.'
c. Zhangsan zhuang-dào le anquandao
Zhangsan bump-arrive PERF median
'Zhangsan bumped into the median.'


Regarding the examples shown in (9), (9b) and (9c) are more commonly used than (9a) by native speakers. Example (9a) only describes a past/perfective event that just happened with the use of perfective le. Compared with $(9 \mathrm{c})$, the $\mathrm{VC}$ dào is used to specifically emphasize the confirmation of the action $V_{1}$ as well as the telic concept. Apparently, it seems that the example (9) is compatible with Teng's (1977) claim that both shàng and dào contains the semantic component 'contact'. However, there is no need to explain the function of dào by using the notion of spatial contact. On the contrary, when the satellite shàng is used in (9b), this sentence just explicitly designates the spatial configuration between the Figure (the unspecified car that Zhangsan drove) and Ground (anquandao 'median'). This example provides additional evidence for confirming that the satellite shàng is a poly-functional VC.

\subsection{Aspect: Complementary Distribution}

The satellites shàng and dào do not all behave alike with respect to the notion of aspect. In example (10), satellites shàng and dào both function as an event of temporal contouring (Aspect). If there is no $\mathrm{VC}$ used but a perfective marker le is used in (10a), the only meaning expressed by the verb hua 'spend' is the perfective or the past meaning of spending. However, if the VC shàng is used, not only the completion of the action is evoked, but the inception plus the duration of $\mathrm{V}_{1}$ hua 'spend' is semantically signified. The focus is from starting, remaining, and intensifying the duration of the $\mathrm{V}_{1}$; in particular, the duration is longer than the speaker's expectation (presupposition). As we observe in (10b), the addition of shàng not only denotes an inception of another new state, but it also implies the duration of the $\mathrm{V}_{1}$. However, this is in contrast to the satellite dào, which cannot be used in (10c) since the aspect marker dào only denotes the telic notion of the event.
$\begin{array}{llllll}\text { a. Zhangsan } & \text { hua-(le) } & \text { ershi-ge } & \text { xiaoshi } & \text { xie } & \text { qimo-baogao } \\ \text { Zhangsan } & \text { spend-PERF } & \text { twenty-CL } & \text { median } & \text { write } & \text { final-report }\end{array}$ 'It took/has taken Zhangsan twenty hours to write the final paper.'
b. Zhangsan hua-shàng ershi-ge xiaoshi xie qimo-baogao Zhangsan spend-up twenty-CL median write final-report 'It took/has taken Zhangsan twenty hours to write the final paper.'
c. *Zhangsan hua-dào ershi-ge xiaoshi xie qimo-baogao Zhangsan spend-arrive twenty-CL median write final-report

In a nutshell, the VCs shàng and dào are incorporated with different aspectual components. The VC dào signals a telic notion, whereas shàng specifies a telic plus an inception notion, yielding a certain degree of duration. This explains why the example (10c) is ungrammatical if the aspectual marker dào, denoting the duration of the event, is used. The contrast between shàng and dào can be 


\section{Hui-Chen Sabrina Hsiao}

expanded to reveal their fundamental aspectual complementarity in state change or realization framing events later.

\subsection{Realization: Confirmation vs. Fulfillment Satellites}

In an event of realization, I demonstrate that shàng and dào function differently in terms of fulfillment or confirmation. The satellite shàng functions as either a fulfillment or a confirmation satellite, whereas dào mainly functions as a fulfillment satellite. Additionally, the different roles of the satellite shàng depend on the use of the first verb. As illustrated in (11), the referent of the transitive verb guan 'close' consists of an Agent's intended activity of closing and the Agent's further intention that this activity will lead to fulfilling the action - closing the door.

(11) Moot-fulfillment verb: action + goal (i.e. guan 'close')

Fulfillment satellite: shàng 'up' (with fulfillment of the goal)

a. Chumen shi, jide yao ba men guan le Go out time remember want BA door close ASP 'Be sure to close the door when you are going out.'

b. Chumen shi, jide yao ba men guan-shàng Go out time remember want BA door close-up 'Be sure to close the door when you are going out.'

c. *Chumen shi, jide yao ba men guan-dào Go out time remember want $\mathrm{BA}$ door close-arrive

Basically, the meanings of (11a) and (11b) are the same and the use of the satellite shàng 'up' just further fulfills the goal of the action $\mathrm{V}_{1}$ guan 'close'. It is plausible to argue that the additional use of the satellite shàng conceptually leads to the beginning of the resultant state change. That is to say, without a satellite in (11a), this verb is moot regarding the outcome, and the sentence just expresses an action of "closing the door". The intended result expressed by the verb guan 'close' is originally potential, but the addition of the satellite shàng 'up' indicates that the inception of this state change has actually been fulfilled in (11b). Therefore, this type of event can also be regarded as a kind of state change, from potential action to actual realization. On the other hand, the VC dào in (11c) is not allowed in this construction because the aspectual notion of dào does not indicate the inception of the resultant state change.

Let's look further at the other examples given in (12). First, one remarkable thing to note is the similar meaning illustrated in both (12a) and (12c), but with additional implication signified by the use of dào in (12c). 
(12) Moot-fulfillment verb: action + goal (i.e. mai 'buy')

Fulfillment satellite: dào 'arrive' (with fulfillment of the goal)
a. Zhangsan mai-le
Zhangsan buy-PERF
zhe-zhang changpian
'Zhangsan bought this record.'
this-CL record
b. *Zhangsan mai-shàng (le) zhe-zhang changpian Zhangsan buy-up PERF this-CL record
c. Zhangsan mai-dào (le) zhe-zhang changpian Zhangsan buy-arrive PERF this-CL record

'Zhangsan bought this record (implication: through an effort).'

Likewise, the single verb mai 'buy' in (12a) is a moot-fulfillment verb, and the outcome is indeterminate without employing any verb complements. With the fulfillment satellite dào used in (12c), the implication of the sentence is that one made a lot of effort in order to buy the record. This reading is quite different from (12a), in that there is no such implication involved in the use of the perfective marker le. That is, in (12c), dào not only denotes the completion of the action of buying, but also implies that the effort (i.e. looking, searching, and finally buying) that one had devoted has finally been realized. Second, unlike the previous example (11), the satellite shàng is not allowed in (12b) instead. Notice that if the aspectual notion (telicity) denoted by the verb complement is saliently construed and if there is no spatial relation such as the notion of path involved, the use of the satellite shàng is ungrammatical. In contrast with the satellite shàng, the VC dào is preferred in (12c) to purely denote the fulfillment of the buying action as well as telicity.

On the other hand, in addition to functioning as a fulfillment satellite, shàng also functions as a confirmation satellite, as shown in (13).

(13) Attained-fulfillment verb: action + goal + fulfillment of that goal

Pleonastic satellite: fulfillment of the goal (confirmation of implicature)
a. Zhangsan haishi pei-le shiyi tai-bi
Zhangsan still compensate for-PERF ten-billion Taiwan-unit
'Zhangsan still suffered a loss of ten billion Taiwan dollars.'
$\begin{array}{lllll}\text { b. Zhangsan } & \text { haishi } & \text { pei-shàng } & \text { shiyi } & \text { tai-bi } \\ \text { Zhangsan } & \text { still } & \text { compensate for-up } & \text { ten-billion } & \text { Taiwan-unit }\end{array}$
'Zhangsan still suffered a loss of ten billion Taiwan dollars.'
(p.s. The amount of money is higher than the ordinary people's expectation)
c. *Zhangsan haishi pei-dào shiyi tai-bi
Zhangsan still compensate for-arrive ten-billion Taiwan-unit


In Mandarin, pei 'compensate' is an attained-fulfillment verb, and the use of $p e i$ 'compensate' indicates the actual fulfillment of the intention rather than just an implicature of the fulfillment of the further intention or a moot outcome. The fulfillment of the intention is essentially embodied by the verb itself. The pleonastic satellite shàng is just used to further denote the resultant state, implying the confirmation of that implicature of $\mathrm{V}_{1}$. Thus, this use of shàng involves a certain degree of the inception of another state. We can say that the satellite shàng is responsible for the reading about the speaker's surprise feeling toward the amount of money being compensated for. As seen in (13b), the amount of money for the compensation is higher than the ordinary people's assumption. In general, the VC shàng does implicitly express such a notion - the mental space. As discussed above, dào does not indicate the beginning of another event or change of state. The reason for the satellite dào being incompatible in (13c) is because the satellite dào does not function as a confirmation satellite.

\section{Conclusion}

In this paper, it has been shown that the VCs, shàng 'up' and dào 'arrive' in Mandarin mainly differ in three aspects. First, if the spatial notion is more saliently construed than the aspectual notion by the speaker, shàng vs. dào can occur in the same environment with regard to being VCs. However, the use of shàng further specifies the spatial configuration between the Figure and Ground (i.e. path, surface contact, or spatial relation between the Figure and Ground), whereas dào only denotes the aspectual notion. Second, with respect to the notion of aspect, dào only denotes a telic notion, whereas shàng denotes a telic plus an inception of resultant state from the first verb. Third, in a framing event of realization, dào primarily functions as a fulfillment satellite, whereas shàng is a confirmation satellite as well as a fulfillment satellite, dependent on the first verb.

In summary, I have addressed the issue of the nature of the differences between VCs shàng and dào in Mandarin. Furthermore, I have also proposed an adequate account for some of these differences from a cognitive perspective. My analysis regularizes the seemingly diverse functions of two VCs, shàng and dào, occurring in similar syntactic environments, and also captures their subtle semantic distinctions. It reveals that neither postulating lexical rules nor collocation groups will clarify the nuances between the VCs shàng and dào. On the other hand, this account also serves to justify that there is no single distinct function exhibited by Mandarin VCs. Instead, the meanings and functions of VCs in Mandarin are comprised of a complex of conceptual categories, and each differs by a certain degree of salient manifestation of spatial or aspectual notions.

\section{References}

Chao, Yuen-Ren. 1968. A Grammar of Spoken Chinese. Berkeley and Los Angeles: University of California Press. 
Gao, Shifan. Ed. 1995. Zhengzhong Xing-Yin-Yi Dictionary. Taipei: Zhengzhong Bookstore.

Johnson, M. 1987. The Body in the Mind: The Bodily Basis of Meaning, Imagination, and Reason. Chicago: University of Chicago Press.

Kang, Jian. 2001. Perfective aspect particles or telic aktionsart markers? - Studies of the directional verb compounds. Journal of Chinese Linguistics 29(2): 281-339.

Li, Charles N. and Sandra A. Thompson. 1981. Mandarin Chinese: A Functional Reference Grammar. Berkeley and Los Angeles: University of California Press.

McDonald, Edward. 1994. Completive verb compounds in Modern Chinese: A new look at an old problem. Journal of Chinese linguistics 22(2): 317-362.

Poteet, Stephen. 1987. Paths through different domains: A cognitive grammar analysis of Mandarin dao. Proceedings of the 13th Annual Meeting of the Berkeley Linguistics Society, 408-421. Berkeley, CA: Berkeley Linguistics Society.

Scott, Amanda. 1989. The vertical dimension and time in Mandarin. Australian Journal of Linguistics 9(2): 295-314.

Smith, Carlotta. 1990. Event types in Mandarin. Linguistics 28: 309-336.

Talmy, Leonard. 1985. Lexicalization patterns: Semantic structure in lexical forms. In Timothy Shopen (ed.) Language Typology and Syntactic Description. Vol.3, 36-149. Cambridge: Cambridge University Press.

Talmy, Leonard. 2000. Toward a Cognitive Semantics. Volume II: Typology and Process in Conceptual Structuring. Cambridge, MA: MIT Press.

Teng, Shou-hsin. 1977. A Grammar of verb particles in Chinese. Journal of Chinese Linguistics 5: 1-25.

Thompson, Sandra A. 1973. Resultative verb compounds in Mandarin Chinese. Language 49(2): 361-379.

Xing, Janet. 2000. Pedagogical grammar of Chinese: Spatial and temporal expression. Journal of the Chinese Language Teachers Association, 75-90.

Yong, Shin. 1997. The grammatical functions of verb complements in Mandarin Chinese. Linguistics 35: 1-24.

Zhang, Lihua. 1999. Metaphorical thinking in Chinese shang and xia. In Gerald F. Carr, Wayne Harbert, and Lihua Zhang (eds.) Interdigitations: Essays For Irmengard Rauch, 439-448. New York: Peter Lang.

Hui-Chen Sabrina Hsiao

609 Baldy Hall

University at Buffalo, The State University of New York

Buffalo, NY 14261

hhsiao2@buffalo.edu 